\title{
Duque de Caxias-Rio de Janeiro: contradições entre crescimento econômico e desenvolvimento social
}

Duque de Caxias-Rio de Janeiro: contradictions between economic growth and social development

Duque de Caxias-Rio de Janeiro : les contraditions entre croissance économique et développement social

Duque de Caxias - Rio de Janeiro: contradicciones entre crecimiento económico y desarrollo social.

\section{Fernando Ribeiro Camaz}

\section{(2) OpenEdition}

\section{Journals}

Edição electrónica

URL: http://journals.openedition.org/espacoeconomia/2061

DOI: 10.4000/espacoeconomia.2061

ISSN: 2317-7837

\section{Editora}

Núcleo de Pesquisa Espaço \& Economia

Refêrencia eletrónica

Fernando Ribeiro Camaz, « Duque de Caxias-Rio de Janeiro: contradições entre crescimento econômico e desenvolvimento social », Espaço e Economia [Online], 7 | 2015, posto online no dia 14 abril 2016, consultado o 30 abril 2019. URL : http://journals.openedition.org/espacoeconomia/2061 ; DOI : 10.4000/espacoeconomia.2061

Este documento foi criado de forma automática no dia 30 Abril 2019.

(c) NUPEE 


\title{
Duque de Caxias-Rio de Janeiro: contradições entre crescimento econômico e desenvolvimento social
}

\author{
Duque de Caxias-Rio de Janeiro: contradictions between economic growth and \\ social development \\ Duque de Caxias-Rio de Janeiro : les contraditions entre croissance économique \\ et développement social \\ Duque de Caxias - Rio de Janeiro: contradicciones entre crecimiento económico y \\ desarrollo social.
}

Fernando Ribeiro Camaz

\section{Introdução}

1 O município de Duque de Caxias está localizado na Baixada Fluminense, região que engloba, historicamente, desde a área da Baía da Ilha Grande até Campos dos Goytacazes, no limite com o Espírito Santo - atualmente, refere-se particularmente ao entrono imediato da metrópole no lado oeste da Baía de Guanabara. Para nos situarmos quanto às peculiaridades que envolvem o município em questão, vamos acompanhar as regras usadas pelo Instituto Brasileiro de Estatística e Geografia (IBGE), que classificam, para efeito de estudo, o território em seis níveis hierárquicos. Esta sistemática parte do macro para o microuniverso, começando pelo país, passando replicando pelas regiões, estados, mesorregiões e microrregiões, até chegar aos municípios de forma individual.

2 Segundo esta linha de classificação e seus conceitos, as mesorregiões são subdivisões dentro dos estados brasileiros que congregam diversos municípios dentro de uma área geográfica específica, que apresentam similaridades econômicas e sociais. Criadas pelo IBGE são utilizadas para fins estatísticos e não constituem, portanto, uma entidade política ou administrativa. Como já dito, e, seguindo esta linha de raciocínio, microrregião, de acordo com a Constituição Brasileira de 1988, é um agrupamento de 
municípios limítrofes, cuja finalidade é integrar a organização, o planejamento e a execução de funções públicas de interesse comum, definidas por lei complementar estadual.

3 No Brasil, os municípios são uma circunscrição territorial dotada de personalidade jurídica e com certa autonomia administrativa, sendo as menores unidades autônomas da Federação. Atualmente, são 5.570 municípios distribuídos em 27 unidades da Federação. 0 estado do Rio de Janeiro esta dividido em 92 municípios.

O município de Duque de Caxias está localizado na Região Metropolitana do estado do Rio de Janeiro, possui população de 855.046 habitantes, apresentando densidade demográfica de 1.826 pessoas por $\mathrm{km}^{2}$ - a $8^{\mathrm{a}}$ maior do estado, segundo o Censo 2010, realizado pelo Instituto Brasileiro de Geografia e Estatística (IBGE). O total de 590.370 eleitores representou 5,09\% dos 11,6 milhões de eleitores do Rio de Janeiro, configurando-se o 3.․ colégio eleitoral fluminense. Ainda de acordo com o Censo de 2010, 99,6\% da população é urbana e apenas $0,4 \%$ é rural.

No ranking dos municípios que representavam $25 \%$ do Produto Interno Bruto (PIB) nacional em 2002, Duque de Caxias ocupava a $6^{a}$ posição, atrás apenas de São Paulo, Rio de Janeiro, Brasília, Manaus e Belo Horizonte, respectivamente. Segundo o relatório publicado pelo IBGE sobre o PIB dos municípios do país em 2004, Duque de Caxias ocupava a $7^{a}$ posição na região Sudeste, ficando atrás apenas das capitais São Paulo, Rio de Janeiro e Belo Horizonte, e dos municípios de Campos, Macaé (RJ) e Guarulhos (SP). O PIB per capita do município em 2007 era de $\mathrm{R} \$ 33.398,00$.

O município de Duque de Caxias tem como base do seu crescimento econômico o refino do petróleo, operado na Refinaria de Duque de Caxias (REDUC), localizado no seu segundo distrito, Jardim Primavera, onde também está localizada a sede municipal desde 1991. Em 1999 este município correspondia a 0,8\% do PIB do Brasil e em 2002 ele já apresentava o $6^{\circ}$ lugar no ranking do PIB brasileiro, com $1 \%$. 0 setor de Petróleo e Gás, especificamente no que se refere à participação da área petroquímica, foi responsável pela inclusão de municípios fluminenses, como Campos, Macaé e Duque de Caxias entre os nove primeiros.

\section{Localização da Refinaria Duque de Caxias}

7 O município de Duque de Caxias apresentou um grande crescimento nos últimos anos, com ênfase em dois setores, a indústria e o comércio, entre as suas principais atividades econômicas. O município possui cerca de 810 indústrias e 10 mil estabelecimentos comerciais instalados. Segundo o IBGE, o município de Duque de Caxias registrava o sexto maior PIB (Produto Interno Bruto 1999 - 2002) no ranking nacional e o segundo maior do estado do Rio de Janeiro, em um total de R\$14,06 bilhões. A cidade ainda hoje, ocupa o segundo lugar no ranking de arrecadação de ICMS do Estado, perdendo somente para a capital. Podemos visualizar na figura 2, a localização da Refinaria de Duque de Caxias e a Baia de Guanabara. 
Figura 1 - Localização da Refinaria de Duque de Caxias

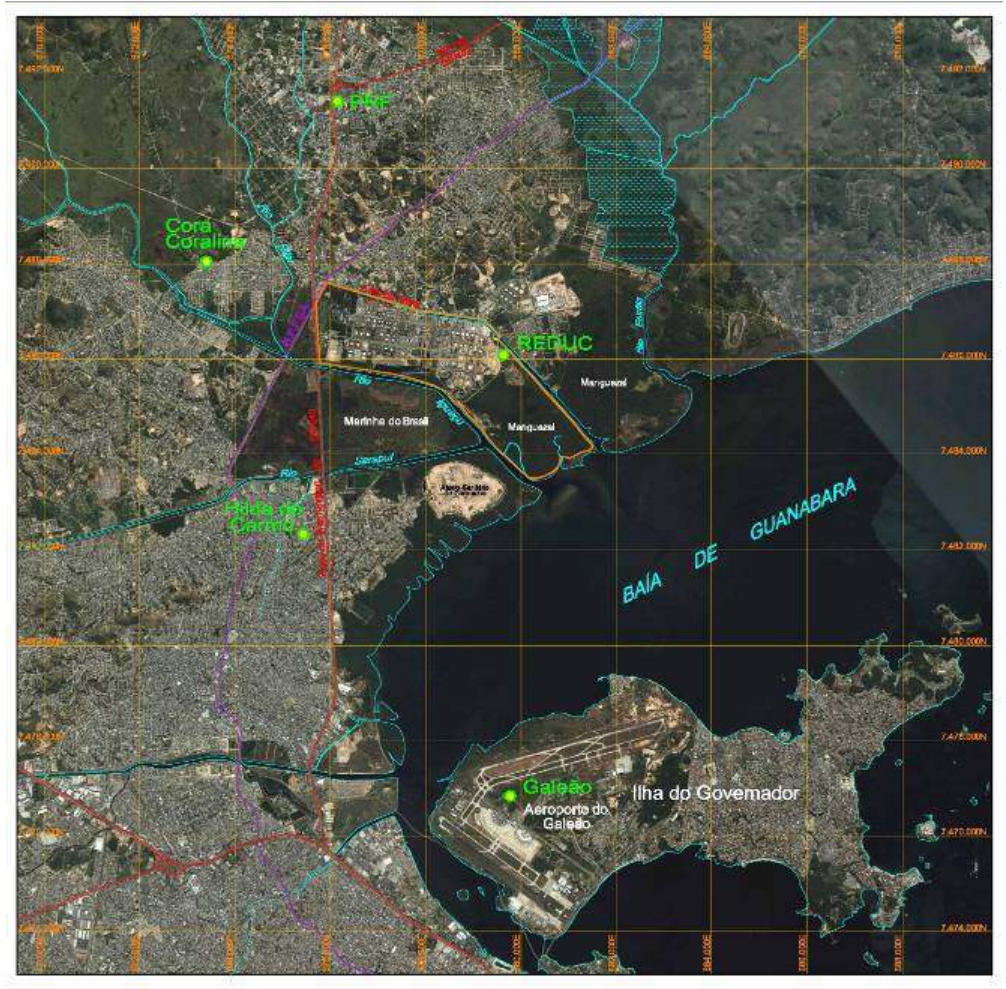

FONTE: DIgITAL GLOBE (2007)

Quanto à educação no município, podemos afirmar, segundo dados do Estudo Socioeconômico dos Municípios Fluminenses, elaborado pelo Tribunal de Contas do Estado do Rio de Janeiro, o número total de matrículas nos ensinos infantil, fundamental e médio de Duque de Caxias, em 2009, foi de 209.209 alunos, tendo involuído para 193.376 em 2010, apresentando variação de $-7,6 \%$ no número de estudantes.

Empresas de vários segmentos têm-se instalado em Duque de Caxias, tais como o Jornal o Globo e o Carrefour, aproveitando a privilegiada posição do município, próximo das principais rodovias brasileiras: Linha Vermelha, Linha Amarela, Rodovia Presidente Dutra, Rodovia Washington Luiz e Avenida Brasil, além da proximidade do Aeroporto Internacional Tom Jobim e a distância de apenas $17 \mathrm{~km}$ do Centro do Rio, levando seus produtos facilmente para grandes centros consumidores: São Paulo, Minas Gerais e Sul do Brasil.

O maior parque industrial do Rio de Janeiro fica no município, tendo empresas cadastradas como Texaco, Shell, Esso, Ipiranga, White Martins, IBF, Transportes Carvalhão, Sadia, Ciferal, entre outras. O segmento está mais concentrado nos setores de química e petroquímica, estimulados pela presença da REDUC, a segunda maior do país que possui um Polo Gás-Químico e conta com a Usina Termelétrica (Leonel Brizola), conhecida como Termorio.

11 A Refinaria de Duque de Caxias (REDUC) embora seja a maior empresa do setor petroquímico no município e a maior geradora de empregos, tem $70 \%$ de sua mão-de-obra importada de outros municípios do Estado, o que compromete a inserção na economia local da riqueza produzida pela empresa. Fica, portanto, a população local restrita a empregos indiretos gerados por empresas terceirizadas, cujas atividades são menos 
sofisticadas com níveis de remuneração menores. No cadastro industrial da Firjan, Duque de Caxias ocupa a segunda posição em número de empregados no Rio de Janeiro e a terceira em número de estabelecimentos, atrás apenas da própria capital e de Petrópolis.

Os principais segmentos industriais são: químico, petroquímico, metarlúgico, gás, plástico, mobiliário, têxtil e vestuário. Apesar de um contexto que combina forte crescimento econômico nacional e consistente diversificação da economia fluminense, Duque de Caxias não experimenta um ciclo virtuoso caracterizado por elevados níveis de investimentos produtivos e em infraestrutura dentro do município, atraídos por suas vantagens comparativas.

Conforme podemos visualizar na figura 3, através do número de pessoas admitidas e desligadas por setores de ocupação formal em Duque de Caxias (período de janeiro a outubro de 2010). De forma correspondente, são essas três áreas que mais movimentam o mercado com admissões e desligamentos ao longo do ano (figura 3).

Figura 2: Número de pessoas admitidas e desligadas por setores de ocupação em Duque de Caxias.

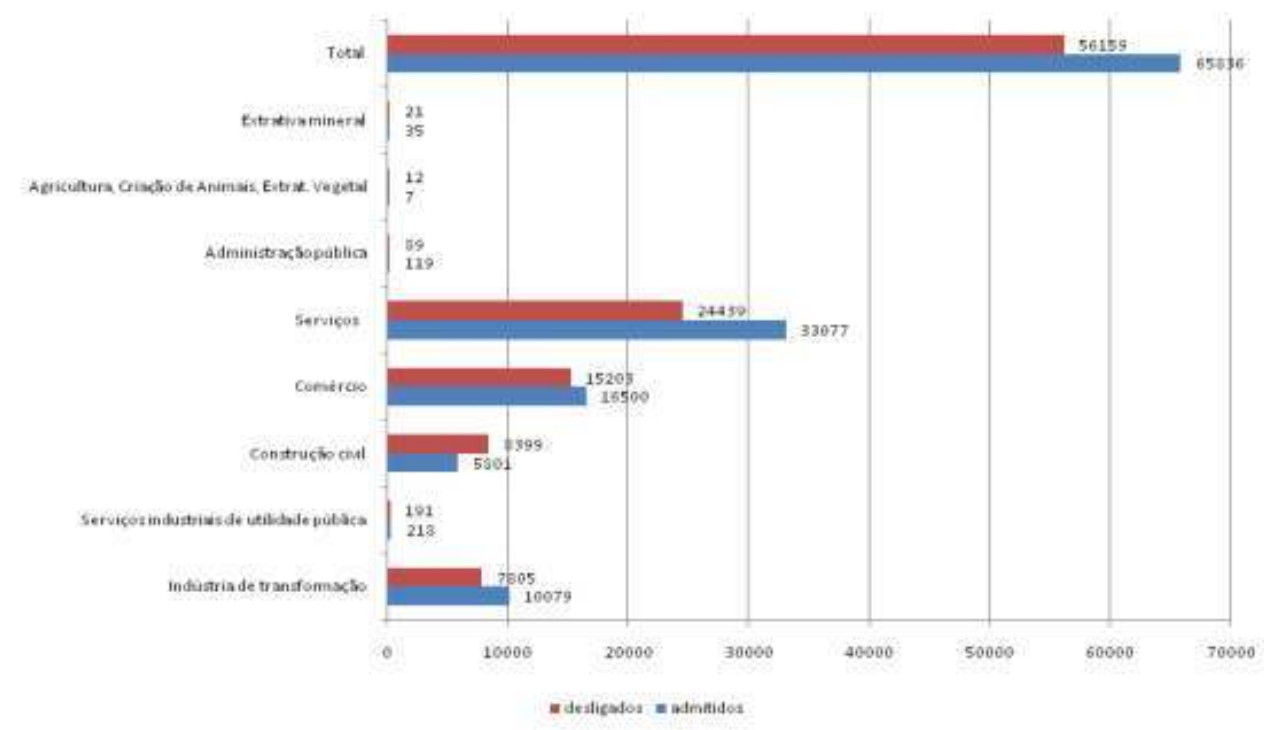

Fonte: www.caged.gov.br. Acesso em 06/12/2010. melhoria generalizada da capacidade dos atores públicos e privados em reduzir os desequilíbrios socioambientais, com resultado no incremento da qualidade de vida da população duque caxiense, aliado a integração ao processo de desenvolvimento da cidade.

\section{Caracterização do mercado de trabalho formal}

De acordo com o Cadastro Geral de Empregados e Desempregados (CAGED), foi possível caracterizar o perfil do mercado de trabalho formal do município. As três principais atividades que empregam a população caxiense são: serviços, comércio e indústria de transformação, respectivamente (figura 4). Conforme podemos visualizar na figura 4, os principais setores econômicos e o percentual de empregabilidade por áreas, em 06 de dezembro de 2010, Duque de Caxias. 
Figura 3: Cadastro Geral de Empregados e Desempregados.

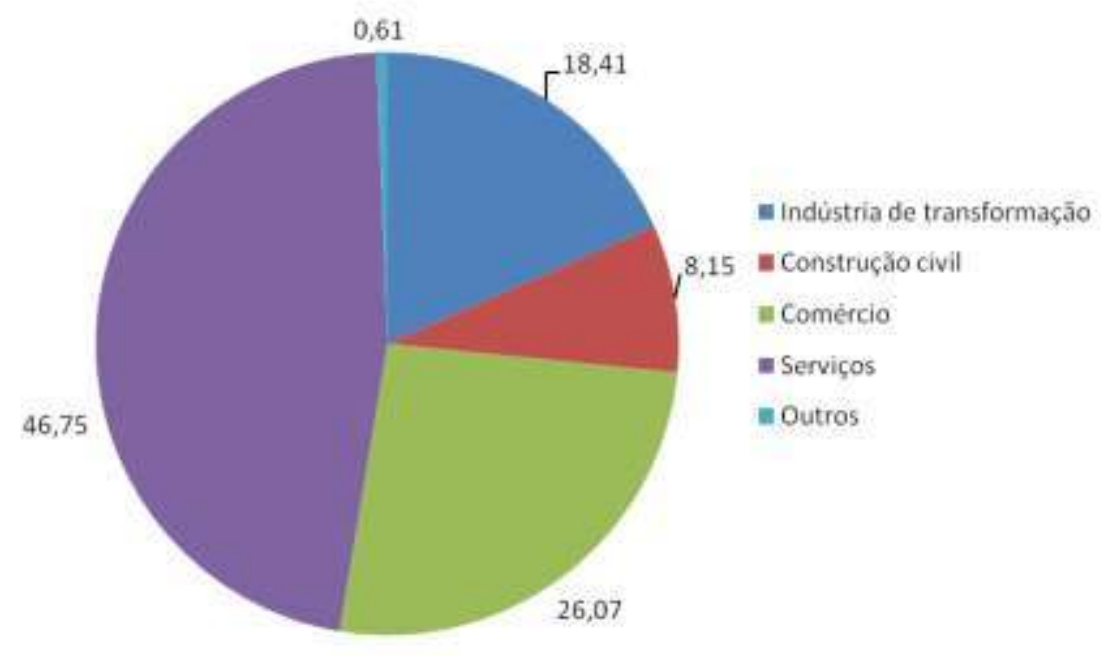

Fonte: www.caged.gov.br. Acesso em 06/12/2010.

16 Desde a emancipação do município, vários fatores econômicos e sociais contribuíram para o seu crescimento populacional que aumentou em $1.422 \%$ nas suas três primeiras décadas de existência. Na década de 1960, a instalação da Refinaria de Duque de Caxias (REDUC) e a formação de um complexo industrial composto por petroquímicas e distribuidoras de gás de cozinha e combustível tornaram-se atrativos à migração de habitantes do interior do Rio de Janeiro e de outros Estados. Outro fator que concorreu para o aumento populacional em Duque de Caxias, ainda na década de 1960, foi à especulação imobiliária na cidade do Rio de Janeiro, quando uma parcela da população carente deste município, em sua maioria de baixa escolaridade e sem qualificação profissional, transferiu-se para os municípios próximos, mantendo vínculo empregatício no centro da metrópole. Contudo, segundo Albuquerque, (1994:89) e Lago (2000), essa ocupação crescente não teria sido acompanhada de obras suficientes de infraestrutura urbana.

17 Segundo IBGE, Duque de Caxias é o quarto município do Estado em população, com densidade demográfica alta e crescimento populacional, acelerado. A densidade demográfica do município é de 1800 pessoas por $\mathrm{Km}^{2}$, a $8^{\circ}$ do estado. A taxa média geométrica de crescimento anual para os anos de $91 / 96$ foi de 1,38\%, muito maior do que as médias do Estado $(0,92 \%)$ e da região metropolitana (0,76\%). A taxa de crescimento anual estimada de $0,7 \%$ com esperança de vida ao nascer de 67,49 anos. A população residente estimada do município, em 2009, era de 872.762 habitantes. Conforme podemos visualizar na figura 5, o gráfico a seguir mostra o crescimento populacional de Duque de Caxias de 2000 a 2009. 
Figura 4: População residente/Estimativas utilizadas pelo TCU para determinação das cotas do Fundo de Participação dos Municípios -- FPM.

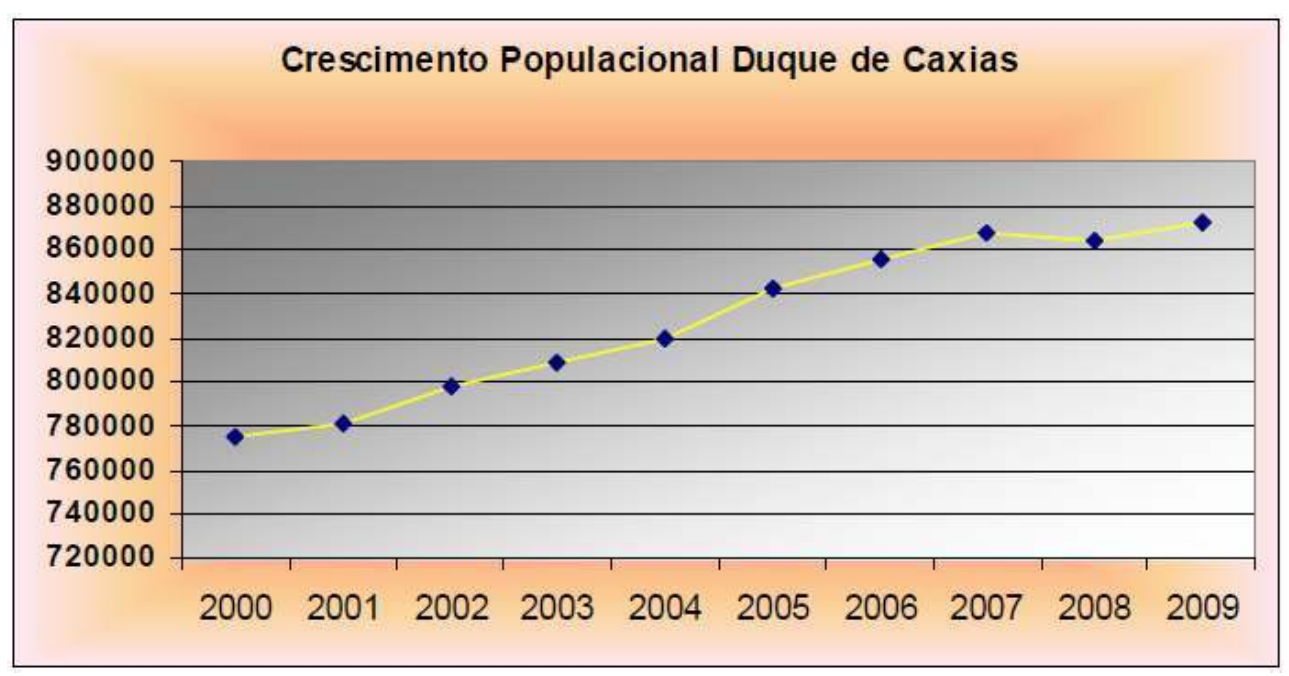

Fonte: DATASUS

\section{Índice de Desenvolvimento Humano (IDH)}

O objetivo da elaboração do Índice de Desenvolvimento Humano é oferecer um contraponto a outro indicador muito utilizado, o PIB per capita, que considera apenas a dimensão econômica do desenvolvimento. O IDH pretende ser uma medida geral, sintética do desenvolvimento humano. Ele parte do pressuposto de que para aferir o avanço de uma população não se deve considerar apenas a dimensão econômica, mas também outras características sociais, culturais e políticas que influenciam a qualidade da vida humana (Programa das Nações Unidas para o Desenvolvimento, 2010).

O Índice de Desenvolvimento Humano (IDH) é uma medida comparativa obtida pela média aritmética simples de três dimensões ou subíndices: longevidade (esperança de vida); educação (taxa de alfabetização de adultos e taxa de escolarização) e da renda (PIB per capita ajustado) e é uma forma padronizada de avaliação e medida do bem-estar de uma população.

O índice varia de zero até 1 , sendo considerado:

muito alto, maior ou igual a 0,800 até 1,000 (1 município);

alto, quando maior ou igual a 0,700 até 0,799 (57 municípios);

médio, de 0,600 a 0,699 (34 municípios);

baixo, entre 0,500 e 0,599 (nenhum município);

muito baixo, entre 0 e 0,499 (nenhum município).

O IDH de Duque de Caxias calculado em 2000, pelo IBGE, revela um IDH de 0,753, ocupando o $52^{\circ}$ lugar no Estado do Rio de Janeiro onde o Município de Niterói tem o $1^{\circ}$ maior valor de IDH $(0,886)$. Mas se na virada do milênio, Duque de Caxias começava a expressar um crescimento econômico de fôlego, o mesmo não se vê em sua situação social. O IDH-M brasileiro em 2002 teve a media de 0,764. O IDH-M de Duque de Caxias teve no ano 2000 o valor de 0,753 , estando em $56^{\circ}$ lugar no estado e em $1796^{\circ}$ no Brasil. 
27 Já IDH de Duque de Caxias calculado em 2010, ano do último censo completo do IBGE, revela um discreto aumento no IDH que subiu para 0,711, ocupando o $49^{\circ}$ lugar no Estado do Rio de Janeiro e a modesta posição de $1574^{\circ}$ no Brasil. Conforme podemos visualizar na figura 6, a tabela com o ranking do IDHM dos Municípios de 2010 (com dados dos Censos 1991, 2000 e 2010).

Figura 5: Ranking do IDHM dos Municípios de 2010.

\begin{tabular}{|c|c|c|c|c|c|}
\hline \multicolumn{6}{|c|}{ Ranking IDHM Municípios 2010} \\
\hline $\begin{array}{c}\text { Ranking IDHM } \\
2010\end{array}$ & Municipio & IDHM 2010 & $\begin{array}{c}\text { IDHM Renda } \\
2010\end{array}$ & $\begin{array}{c}\text { IDHM } \\
\text { Longevidade } \\
2010\end{array}$ & $\begin{array}{c}\text { IDHM } \\
\text { Educação } \\
2010\end{array}$ \\
\hline $1^{\circ}$ & $\begin{array}{l}\text { São Caetano do Sul } \\
\text { (SP) }\end{array}$ & 0,862 & 0,891 & 0,887 & 0,811 \\
\hline $2^{\circ}$ & $\begin{array}{c}\text { Á guas de São Pedro } \\
\text { (SP) }\end{array}$ & 0,854 & 0,849 & 0,89 & 0,825 \\
\hline $3^{\circ}$ & Florianópolis (SC) & 0,847 & 0,87 & 0,873 & 0,789 \\
\hline $4^{\circ}$ & $\begin{array}{c}\text { Balneário Camboriú } \\
\text { (SC) }\end{array}$ & 0,845 & 0,854 & 0,894 & 0,805 \\
\hline $5^{\circ}$ & Vitória (ES) & 0,845 & 0,876 & 0,855 & 0,807 \\
\hline $6^{\circ}$ & Santos (SP) & 0,84 & 0,861 & 0,852 & 0,773 \\
\hline $7^{\circ}$ & Niterói (RJ) & 0,837 & 0,887 & 0,854 & 0,771 \\
\hline $8^{\circ}$ & Joaçaba (SC) & 0,827 & 0,823 & 0,891 & 0,768 \\
\hline $9^{\circ}$ & Brasilia (DF) & 0,824 & 0,863 & 0,873 & 0,742 \\
\hline $10^{\circ}$ & Curitiba (PR) & 0,823 & 0,85 & 0,855 & 0,768 \\
\hline $45^{\circ}$ & Rio de Janeiro (RJ) & 0,84 & 0,845 & 0,719 & 0,799 \\
\hline $220^{\circ}$ & $\begin{array}{c}\text { Volta Redonda } \\
\text { (RJ) }\end{array}$ & 0,771 & 0,763 & 0,833 & 0,72 \\
\hline $249^{\circ}$ & Resende (RJ) & 0,768 & 0,762 & 0,839 & 0,709 \\
\hline $304^{\circ}$ & Macaé (RJ) & 0,764 & 0,792 & 0,828 & 0,681 \\
\hline $1514^{\circ}$ & Nova Iguaçu (RJ) & 0.713 & 0,691 & 0,818 & 0,641 \\
\hline $1574^{\circ}$ & $\begin{array}{c}\text { Duque de Caxias } \\
\text { (RJ) }\end{array}$ & 0,711 & 0,692 & 0,833 & 0,624 \\
\hline $2105^{\circ}$ & Itaborai (RJ) & 0,693 & 0,69 & 0,813 & 0,593 \\
\hline $2439^{\circ}$ & Queimados (RJ) & 0,68 & 0,659 & 0,81 & 0,589 \\
\hline
\end{tabular}

Fonte: Atlas do Desenvolvimento Humano no Brasil, 2013.

O município de Niterói ,apesar de uma pequena queda, continua em primero lugar no estado com o maior valor de IDH $(0,837)$ e ocupando o $7^{\circ}$ lugar a nível nacional. 0 gráfico abaixo compara o IDH de Duque de Caxias com o da capital e com o dos outros municípios da região, com os quais estabelece fronteiras, mostrando o lugar que ocupam no ranking estadual. 
Figura 6: Comparações do IDH de Duque de Caxias com o da capital e com o dos outros municípios da região.

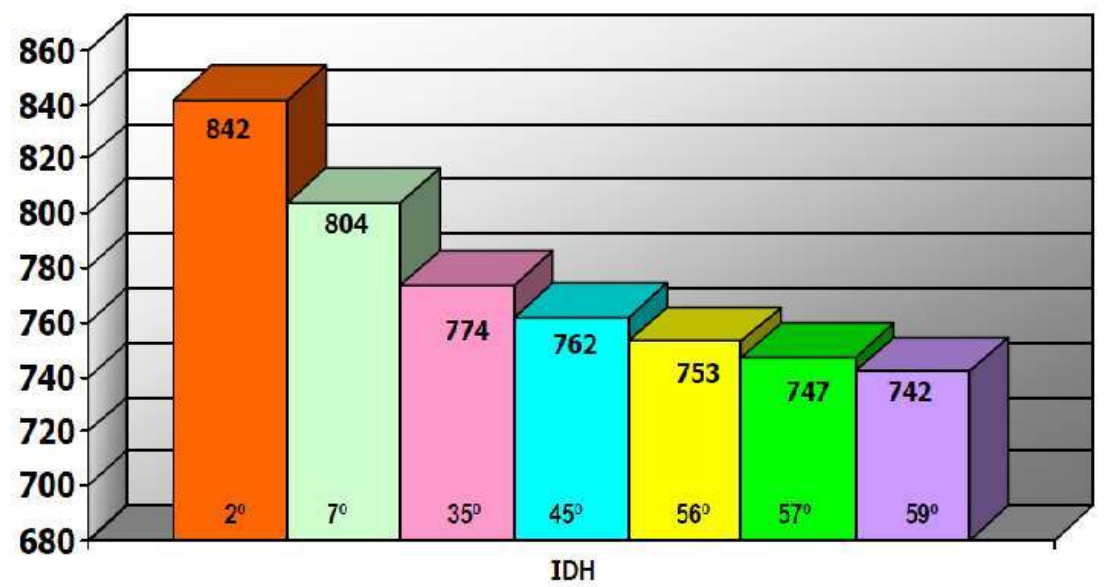

\begin{tabular}{|c|c|}
\hline $\begin{array}{l}\square \text { Rio de Janeiro } \square \text { Petrópolis } \\
\square \text { Duque de Caxias } \square \text { Magé }\end{array}$ & $\begin{array}{l}\text { 口S. João do Meriti } \square \text { Nova Iguaçu } \\
\square \text { Belford Roxo }\end{array}$ \\
\hline
\end{tabular}

Fonte: Plano Municipal de Saúde 2010-2013. Caxias, em relação aos demais municípios da região adjacente a ele não é boa, pois Duque de Caxias possui o terceiro pior IDH dentre os municípios vizinhos. Estes indicadores sugerem que as condições materiais de vida são bastante desfavoráveis em todas as áreas do Município. Sabendo-se que a esperança de vida ao nascer em Duque de Caxias é de 67,49 anos (dados do Programa das Nações Unidas para o Desenvolvimento (PNUD) / Instituto de Pesquisa Econômica Aplicada (IPEA) / Fundação João Pinheiro (FJP)) e que o município possui a segunda maior economia do Estado, como é possivel que Duque de Caixas apresente um IDH que é $056^{\circ}$ do estado e o $1796^{\circ}$ do Brasil? intrigante; logo, temos que questionar como é possível a geração de recursos substanciais, e tudo isso não refletir internamente na melhoria da qualidade de vida da população. A partir disto, indaga-se se: o cerne do desempenho social de Duque de Caxias, não estaria relacionado à gestão de seus recursos?

31 A Região Sudeste, onde se situa o município de Duque de Caxias e o Estado do Rio de Janeiro, é a região geoeconômica mais importante do país, respondendo, juntamente com os estados de São Paulo, Minas Gerais e Espírito Santo, por 55,4\% do PIB brasileiro. O território fluminense, com uma área de $43.766,6 \mathrm{~km}^{2}$, está dividido em 92 municípios agrupados em oito Regiões de Governo (Metropolitana, Noroeste Fluminense, Norte Fluminense, Serrana, Baixadas Litorâneas, Médio Vale Paraíba, Centro-Sul Fluminense e Região da Costa Verde).

De uma forma geral, as capitais concentram especialmente atividades do setor de serviços, como bancos, financeiras, comércio e administração pública. Além das capitais, 11 municípios se destacam na participação do PIB, todos com equilíbrio entre serviços e indústria, agregando 8,6\% da renda do país: Guarulhos, Campinas e Osasco, todos em São Paulo têm cada, $1 \%$ do PIB nacional; São Bernardo do Campo (SP), 0,9\%; Betim (MG), 0,8\%; 
Barueri e Santos (SP), 0,7\% cada; Duque de Caxias e Campos dos Goytacazes (RJ) têm 0,7\% cada; São José dos Campos (SP), 0,6\%; e Jundiaí (SP), 0,5\%.

A Região Metropolitana do Estado do Rio de Janeiro continua concentrando 67,6\% do PIB, apesar de ter perdido 7,5\% em participação no período de 2002 a 2010. Já as Regiões Norte Fluminense $(3,7 \%)$, Costa Verdes $(1,8 \%)$ e Baixadas Litorâneas $(1,1 \%)$ aumentaram suas participações no PIB. Já o município do Rio de Janeiro, com 46,7\%, teve a maior participação, e São José de Ubá, a menor 0,02\%. Estes dados são uma ferramenta de análise setorial, para estudos e planejamento do desenvolvimento sustentável.

Em relação ao desempenho municipal em 2010, cinco municípios se destacaram na liderança das participações no PIB do Estado, mantiveram suas posições no ranking e concentraram $64,9 \%$ da economia fluminense, contra $66,3 \%$ em 2009 : Rio de Janeiro ( $48,2 \%$ em 2009 e 46,7\% em 2010); Duque de Caxias (6,9\% e 6,5\%); Campos dos Goytacazes (5,7\% e $6,2 \%)$; Niterói (2,8\% e 2,7\%); e Macaé (2,7\% e 2,8\%).

A perda de participação do Rio de Janeiro refletiu, em parte, a moderada recuperação do setor extrativo mineral na maior parte dos municípios produtores de petróleo. Já o município de Duque de Caxias sofreu com o aumento nos preços desta matéria-prima, que impactou a atividade de refino, na medida em que expandiu os custos intermediários, reduzindo o valor adicionado do município. A participação do interior retomou sua trajetória de ascensão, passou de 51,8\% para 53,3\%, registrando acréscimo de 1,5\%.

A Região Metropolitana continuou a ter participação preponderante, com 69,1\% em 2009 e $67,6 \%$ em 2010. Dentre as demais regiões, cinco melhoraram seu desempenho: Norte Fluminense (10,3\% em 2009 e 11,2\% em 2010); Médio Vale Paraíba (6,4\% e 7,2\%); Baixadas Litorâneas (5,0\% e 5,3\%); Costa Verde (2,6\% e 2,9\%); e Centro-Sul Fluminense (1,0\% e 1,1\% ). Ao contrário, as Regiões Serrana $(4,2 \%$ e $3,8 \%)$ e Noroeste Fluminense $(1,0 \%$ e $0,9 \%)$ registraram perda de participação. Cabe ressaltar que no Norte Fluminense e nas Baixadas Litorâneas é de suma importância o papel desempenhado pela atividade de extração de petróleo e gás. Na região do Médio Vale Paraíba, a atividade automobilística é a que mais influencia o resultado da sua economia.

O maior PIB per capita em 2010 é o de Porto Real, seguido de Quissamã, São João da Barra, Carapebus e Angra dos Reis, repetindo as cinco primeiras colocações de 2009. Porto Real se destaca pelas atividades do setor automobilístico, Angra dos Reis pela geração de energia elétrica [pela presença das usinas nucleares] e os demais pela exploração do petróleo e gás natural. Os menores PIB per capita encontra-se em Conceição de Macabu, Trajano de Moraes e Aperibé, onde se destaca a presença do setor de Administração Pública.

\section{PIB alto X IDH baixo}

PIB alto não significa, contudo, alto desenvolvimento humano, mostra a pesquisa, e os municípios com as maiores rendas per capita do país aparecem mal colocados no Índice de Desenvolvimento Humano (IDH). Essa situação paradoxal é explicada porque a renda per capita é resultado matemático simples da receita do município dividida pela população, sem levar em conta a distribuição dessa renda nem estatísticas sociais, como saúde ou educação. 0 exemplo limite dessa situação é São Francisco do Conde (BA) que, com 33.172 habitantes, tem uma das mais altas rendas per capita do país ( $\mathrm{R} \$ 296.885,00)$, mas que amarga a $2.743^{a}$ posição na lista do IDH dos municípios brasileiros. A distorção 
acontece porque o município, com IDH de 0,714 , tem uma população pequena, mas abriga uma das maiores refinarias do país.

Ao entender que o município não se resume a uma mera unidade administrativa, sendo um ente federativo do Estado, e que tão pouco se resume ao seu governo, mas reúne governo, sociedade e demais organizações não governamentais, percebe-se que a gestão dos recursos de um município está nas mãos de um amplo corpo social. Neste ponto é pertinente pensar no conceito de desenvolvimento local para elucidar o pífio desempenho social de um município tão rico em cifras como Duque de Caxias.

O conceito de espaço no livro Por uma geografia nova (Milton Santos, 1978), é focal, pois "o espaço é no plano microscópico, como a eletrosfera de um átomo, com um campo de forças com energias desiguais. Em função disso, no plano macro a evolução espacial não se apresenta de igual forma em todos os lugares" (Santos, 1978, p.122). Assim,

o espaço por suas características e por seu funcionamento, pelo que ele oferece a alguns e recusa outros, pela seleção de localização, atividades e entre os homens, é o resultado de uma práxis coletiva que reproduz as relações sociais, [...] o espaço evolui pelo movimento da sociedade total. (SANTOS, 1978, p. 171).

Milton Santos também denomina o espaço como uma instância da sociedade, fator social e não somente como um reflexo social. Ainda, segundo o autor,

o espaço organizado pelo homem é como as demais estruturas sociais, uma estrutura subordinada subordinante. É como as outras instâncias, o espaço, embora submetido à lei da totalidade, dispõe de certa autonomia. (SANTOS, 1978, p. 145).

$O$ do conceito de desenvolvimento local deve negar o progresso material como suficiente para o processo de desenvolvimento e reafirmar a participação popular, o protagonismo comunitário, o empenho pessoal; ou seja, estimular iniciativas e recursos endógenos atuando pelo bem-estar coletivo, como partes suas imprescindíveis, tentaram compreender esta dinâmica como pode esta vultosa entrada de recursos, replicarem em indicadores sociais pífios.

43 No que se refere à economia do município de Duque de Caxias, esta começa a ganhar relevo a partir da metade da década de 90 . Mas, para fins de reflexão, utilizaremos como recorte temporal dos indicadores o período entre 2000 a 2010, quando serão confrontados o desenvolvimento social e o econômico, considerando alguns municípios do entorno.

Sendo urgentes as demandas sociais da população duque caxienses, é possível pensar em mais uma "demora" nos avanços sociais. Portanto, teremos que acompanhar o comportamento de seus indicadores, sociais e econômicos. Sinteticamente, a questão a ser respondida é: há avanços sociais associados ao crescimento econômico local? A partir desta indagação podemos analisar esta problemática do "crescimento econômico versus desenvolvimento social", pois, tendo-se avanços sociais, podemos questionar até onde a participação comunitária, os recursos endógenos e o protagonismo do cidadão estão envolvidos nestas melhorias; caso entendamos que os avanços sociais são modestos podemos questionar quais são os entraves ao desenvolvimento em escala local. Por fim, esta leitura tem o objetivo específico de indicar quais aspectos geográficos, econômicos e sociais se caracterizam como entraves ou fomentos ao desenvolvimento local em Duque de Caxias.

45 A concepção de desenvolvimento econômico e social a partir da geografia não pode prescindir do conceito de lugar. A justificativa para o uso da escala local no estudo sobre desenvolvimento regional é que o lugar é o intermédio entre o mundo e o individuo (SANTOS, 1996), ou seja, é o lugar que materializa as potencialidades do mundo e o coloca 
em simbiose com o individuo. Afinal, "o mundo, porém, é apenas um conjunto de possibilidades, cuja efetivação depende das oportunidades oferecidas pelos lugares" (SANTOS, 1996, p. 23).

O desenvolvimento econômico e social liga-se ao planejamento de médio e longo prazo de políticas públicas e projetos integrados para a cidade, servindo de referência institucional e territorial para articular a discussão do planejamento local, criando espaço para a democratização das decisões, não apenas de demandas imediatas, como a resolução de problemas imediatistas nas áreas sociais e econômicas locais, mas também daquelas decisões que definirão a trajetória do investimento na cidade e seus reflexos na região de influência para as próximas décadas.

Lugar [e cotidiano] são as potências gerais para o desenvolvimento, que se traduzem na gestão de recursos humanos, materiais e imateriais. A gestão dentro de um projeto de desenvolvimento local não deve abrir mão da participação comunitária, o que sugere deliberação popular sobre as ações governamentais de forma qualificada; se as camadas mais populares não possuírem as informações necessárias não poderão auferir o custobenefício desta ou aquela proposta nem contribuírem, refletirem e sugerirem de forma relevante para a resolução dos problemas vividos pela mesma. Para tanto, a participação popular implica descentralização do poder e de informações, valorização dos recursos internos, inclusive o humano, e um planejamento adequado a este fim.

48 A comunidade participa da vida política de seu município quando percebe que pode fazer a diferença, quando não se vê mais como uma força completamente esmagada pela imponência do aparelho estatal. É necessário que o governo não seja visto como algo maciço, movido pelos mesmos tradicionais grupos de poderosos, e inacessível ao cidadão anônimo.

Floriano de Oliveira, alerta quanto à limitação dos planos estratégicos imposta nos planos de desenvolvimento local:

"Com efeito, multiplicam-se os instrumentos de elaboração de planos de desenvolvimento, sem que sejam explicitados os mecanismos que poderiam concorrer para a distribuição da riqueza e a gestão compartilhada do território. São, nesse caso, propostas que mobilizam os poderes públicos para que estes atuem como indutores de um "desenvolvimento econômico local" que, no entanto, é entendido como o resultado da execução de planos estratégicos que visam mobilizar os recursos sociais e naturais, existentes no território, para viabilizar os interesses do capital. Para além das possibilidades reais de desenvolvimento, tais instrumentos, predominantemente, apenas viabilizam o uso do território para os capitais corporativos e isso se evidencia no fato de que apenas os lugares que sejam de interesse direto das empresas logram algum tipo de aprimoramento das forças produtivas". (OLIVEIRA, 2007)

50 Para tanto, a descentralização política se concretiza em uma estrutura institucional mais paritária, clara e fluida. Além disso, o governo local não pode achar que os recursos endógenos serão suficientes para o desenvolvimento. Mais do que simplesmente acompanhar os processos já em andamento, a apresentação dos projetos antes de sua implementação possibilita a comunidade avaliar quais benefícios e danos serão causados; desta maneira, a comunidade poderá intervir a fim de otimizar os recursos utilizados sobre aquela área.

51 Logicamente, se as soluções são locais, isto não significa que são estanques à comunidade. É importante a presença dos governos estadual e federal subsidiando este processo iniciado e conduzido pela população local. A contribuição destas forças deve promover o equilíbrio entre as atividades econômicas do município; da mesma forma, tais forças 
devem desviar da formação de tão somente ilhas tecnológicas isoladas da realidade da força produtiva local, que não dinamizam economicamente o município como um todo. Logo, o conceito de investimento é ampliado, pois se torna a ultrapassagem do entendimento de investimentos como construções materiais ou reposição de capital sobre os serviços públicos. Campanhas de conscientização sobre direitos trabalhistas, educação ambiental, cuidados domésticos com a própria saúde, e coisas afins são exemplos de ações simples, ao alcance do poder municipal, que representam investimentos no capital humano, ou em outras palavras, "investimento não material" (DAWBOR, 1987).

Se os recursos humanos dependem também de investimentos não-materiais ao alcance da administração municipal, isto não difere quanto às infraestruturas físicas ou a situação de domicílio. Mas, neste caso, não se prescinde de uma propriedade política que permita articular o projeto de desenvolvimento local com as outras esferas administrativas. E esta articulação deve estar exposta nitidamente para a comunidade.

Floriano de Oliveira faz considerações quanto à perspectiva de gestão compartilhada e ao uso deste instrumento, relativamente a favor das lutas sociais:

Do ponto de vista da economia, a escala local não se confunde com a esfera municipal, embora tenha se disseminado no Brasil que projetos de desenvolvimento devam ser produzidos nessa esfera. Na esfera do município, é possível a realização de mudanças sociais importantes que melhorem as condições de vida e organização social. Mas como esses objetivos não se dissociam da melhoria geral das condições de trabalho e geração de renda, os planos de integração e crescimento econômico dependem de um uso racional do solo e compartilhamento de fatores situados em espaços sociais muito mais amplos que os territórios municipais. Defendemos, por isso, a gestão compartilhada, tanto internamente ao município, como forma de restringir o patrimonialismo e o jogo de interesses de grupos econômicos locais, quanto para criar maiores níveis de integração econômica entre os municípios, reconhecendo que os fatores produtivos numa economia globalizada não se restringem a uma cidade ou município". (OLIVEIRA, 2007).

Os programas desenvolvidos pela prefeitura têm este papel, de articular recursos endógenos e exógenos a fim de maximizar as potencialidades do município. Esta tarefa, ainda árdua, foi potencializada pela elevação do município a ente federativo, com a nova constituição brasileira de 1988. Hoje os municípios têm maior poder de arrecadação e de autorregulação, permitindo que desenvolvam em sua estrutura, mecanismos de associação e ajuda mútua como os consórcios, e de participação popular como os conselhos municipais ou ainda o orçamento participativo. São as possibilidades abertas ao desenvolvimento local a partir da constituição de 1988.

\section{Considerações finais}

Observando o panorama, é fácil concluir que a solução para a questão da dicotomia entre o IDH versus PIB é a criação de mecanismos que combinem princípios da democracia representativa brasileira e a descentralização das políticas públicas. Deve haver uma profunda mudança no foco dos investimentos - sempre os aportes financeiros em ciência, tecnologia e desenvolvimento estão nos centros e nos "bolsões de riqueza" - com a criação de mais universidades, escolas técnicas, centros de pesquisas, cultura e lazer em áreas menos favorecidas. Os governos municipais, estaduais e a própria gestão federal devem estimular e liderar de forma integrada os investimentos em educação, geração de 
empregos, novos centros de pesquisas e cultura em áreas carentes ou com índices de desenvolvimento humano baixo.

Porém, o que observamos é um tipo de política imediatista que deve ser desestimulada, pois atende apenas aos interesses financeiros de cunho fortemente empresarial, e, estes não refletem os interesses pautados em um projeto de desenvolvimento regional $\mathrm{e}$ nacional consistente que integre o país. Para que este tipo de integração - a melhoria do índice de desenvolvimento humano - se torne real, devemos considerar que todas as regiões do país, em cada uma com suas peculiaridades, são merecedoras da atenção dos Poderes Públicos.

Podemos inferir na necessidade de disseminar novas prioridades, pois em um país de proporções continentais as mesmas deverão chegar das áreas mais prósperas até as mais opacas.

Neste sentido, destacamos que a educação é um exemplo e deve ter um papel fundamental. Mas esta ferramenta deveria ser amplamente patrocinada pelo Poder Público, mobilizando a sociedade e replicando estes valores em toda nação. As estratégias de política educativa podem e devem explorar as margens de autonomia do sistema escolar, bem como apostar na repercussão ao longo da rede da ação exercida sobre os problemas principais. Um e outro processo requerem, contudo, a consciência clara da compatibilidade entre as políticas ensaiadas no nó educativo e aquelas em curso na pluralidade de outros nós estruturais, o que, em democracia, entenda-se bem, passa menos pela imposição de um plano único e central e mais pela consolidação de um quadro regulador onde possam integrar-se, exprimir-se e concorrer os múltiplos projetos sociais que atravessam a sociedade.

Assim, a educação profissional e tecnológica tem de ter, necessariamente, a intencionalidade estratégica do desenvolvimento, recusando, pois, reduzir o seu alcance a mera adaptação da formação escolar e para escolar a necessidades dos empregadores, das forças vivas, do mercado de trabalho, sempre imprecisamente esclarecidas, o que vem a ser, em regra, definido em função do estado conjuntural de diversas relações de força. Avanços substantivos poderão ser possíveis no esclarecimento da questão, levando-se em conta que o sistema educativo, não constituindo apenas um subproduto da estrutura social, deverá estar atento à organização social do trabalho para que amplie as escalas do conhecimento.

Não é possível aceitarmos que hoje, quando observamos o desejo de diversas nações em se apropriarem dos recursos naturais do país, os cidadãos brasileiros continuem tendo suas habilidades e competências desperdiçadas, por falta de uma política educacional, clara e objetiva. Evidenciamos a necessidade de geração de novos profissionais cidadãos que possam desenvolver a integração nacional. As soluções já foram encontradas, os meios existem, o que falta apenas é vontade política. Este quadro de carências, associado à tradição de centralização política, produziu uma estrutura viciada, onde é bastante comum o exercício de práticas clientelistas, que minam os canais de participação cidadã. Nestes casos, a descentralização e municipalização são insuficientes para garantir o exercício da cidadania.

61 O país necessita, portanto, de um projeto de desenvolvimento humano que mescle os fatores econômicos e sociais, integrando os diversos saberes e as fontes de produção. 0 direito aos serviços essenciais como atendimento médico, educação, habitação, são tão importantes quanto o direito à informação para a conformação de cidadãos habilitados a 
atuarem de forma direta na política local. 0 exercício dos direitos políticos é indissociável dos direitos civis e sociais. Daí a crítica permanentemente presente de Paulo Freire (1996, p. 14) "à malvadez neoliberal, ao cinismo de sua ideologia fatalista e a sua recusa inflexível ao sonho e à utopia". Que literalmente, não estejamos abrindo mão dos recursos naturais e humanos por ineficácia de ações governamentais, facilmente superáveis por meio de um projeto de educação.

\section{BIBLIOGRAFIA}

ASSOCIAÇÃO BRASILEIRA DE NORMAS TÉCNICAS. NBR 6023. Informação e documentação: referências - elaboração. Rio de Janeiro: ABNT, 2000.

CAMAZ, Fernando Ribeiro. COMPERJ: Os Aspectos e Impactos Socioambientais Entorno dos Grandes Empreendimentos. SIMPURB 2013. http://www.simpurb2013.com.br/wp-content/ uploads/2013/11/GT10-1514-Fernando.pdf.

DAWBOR, Ladislau. Introdução ao Planejamento Municipal. São Paulo: Ed. Brasiliense, 1987.

ESTUDO SÓCIO ECONÔMICO DE DUQUE DE CAXIAS; NOVA IGUAÇU; E NITERÓI - 2004 e 2006. Tribunal de Contas do Rio de Janeiro. Rio de Janeiro, 2007. Disponível em: http://

saladeimprensa.ibge.gov.br/noticias?id=1\&idnoticia=354\&t=pib-municipios-revela-concentracaodesigualdades-geracao-renda\&view=noticia . Arquivo consultado em $28 \mathrm{de} \mathrm{fev.} \mathrm{de} 2014$.

FREIRE, Paulo. Pedagogia da autonomia: saberes necessários à prática educativa. São Paulo: Paz e Terra, 1996 (Coleção Leitura).

MARTINS, Sergio Ricardo de oliveira. Desenvolvimento Local: questões conceituais e metodológicas. Revista Internacional de Desenvolvimento Local. Vol. 3, n. 5, p. 51-59, Set. 2002.

OLIVEIRA, Floriano José Godinho. Reestruturação econômica, poder público e desenvolvimento social: possibilidades de disputas e de recomposição do poder no território. Scripta Nova. Revista Electrónica de Geografía y Ciencias Sociales. Barcelona: Universidad de Barcelona, 1 de agosto de 2007, vol. XI, núm. 245 (65). Disponível em: http://www.ub.es/geocrit/sn/sn-24565.htm.

PUTNAM, Robert D. Comunidade e Democracia: a experiência da Itália Moderna. Rio de Janeiro: Ed. Fundação Getulio Vargas, 1996.

SANTOS JUNIOR, Orlando Alves dos. Democracia e governo local: dilemas e reforma municipal no Brasil. Rio de Janeiro: Revan: FASE, 2001.

SANTOS, Milton. Sociedade e espaço: a formação social como teoria e como método. Boletim Paulista de Geografia, nº 54, 1977.

SANTOS, Milton. Por uma Geografia Nova. São Paulo: Hucitec, Edusp, 1978.

SANTOS, Milton. A natureza do espaço. São Paulo: Hucitec, 1996.

SOUZA, Aluisio Gama de. Relatório das Contas de Gestão do Governador, Exercício 2010. TCE/RJ, 2011. 


\section{RESUMOS}

Este artigo tem como objetivo avaliar a qualidade de vida dos habitantes do município de Duque de Caxias nos últimos anos a partir da análise do Índice de Desenvolvimento Humano (IDH) e, particularmente, por meio do índice de educação. Localizado na Região Metropolitana do Rio de Janeiro, Duque de Caxias, à revelia do seu crescimento econômico, permanece apresentando pequena evolução das condições sociais de seus moradores.

This paper intends to evaluate life quality of inhabitants of Duque de Caxias in recent years, based on the analysis of the Human Development Index (HDI), and particularly through the education index. Located in the metropolitan area of Rio de Janeiro, Duque de Caxias, ignoring its economic growth, remains with insufficient evolution of social conditions for its residents.

A partir des données de l'IDH et en accentuant les renseignements sur l'éducation, on analyse la qualité de vie de la municipalité de Duque de Caxias - Rio de Janeiro. Localisée dans la région métropolitaine et en situation de croissance économique, les conditions sociales de ses habitants présentent cependant encore une très petite évolution.

Este artículo tiene por objeto, evaluar los incrementos en la calidad de vida de los habitantes del municipio de Duque de Caxias en los últimos años, a partir del análisis del Índice de Desarrollo Humano (IDH) y, particularmente, por medio del Índice de educación. Localizado en la región Metropolitana de Rio de Janeiro, el municipio de Duque de Caxias, al contrario de su crecimiento económico, presenta leves mejorías en las condiciones sociales de sus habitantes.

\section{ÍNDICE}

Palabras claves: Duque de Caixas, crecimiento económico, desarrollo social, Comarca Fluminense, IDH.

Keywords: Duque de Caxias, economic growth, social development, Baixada Fluminense, HDI. Palavras-chave: Duque de Caxias, crescimento econômico, desenvolvimento social, Baixada Fluminense, IDH.

Mots-clés: Duque de Caxias, croissance économique, développement social, Baixada Fluminense, IDH.

\section{AUTOR}

\section{FERNANDO RIBEIRO CAMAZ}

Doutorando em Políticas Públicas e Formação Humana [PPFH / UERJ]. Coordenador didático e professor em cursos de formação e de educação continuada na Escola de Implementação de Programas de Capacitação em SMES - Escola de Gestão \& Negócio / Universidade Petrobras PETRÓLEO BRASILEIRO S. A. Professor dos cursos de MBA da Universidade Castelo Branco e Universidade Candido Mendes. Email: fernandocamaz@hotmail.com 